\title{
Indicador de desenvolvimento institucional municipal: impactos sobre a economia dos municípios brasileiros ^
}

\author{
Lucas Leão ${ }^{1}$ \\ Hilton Manoel Dias Ribeiro ${ }^{2}$ \\ Suzana Quinet de Andrade Bastos ${ }^{3}$ \\ Ana Maria Hermeto 4
}

\section{Resumo}

Diante das disparidades socioeconômicas regionais no Brasil e das teorias que defendem o papel das instituições no desenvolvimento econômico, o presente estudo contempla dois objetivos complementares. O primeiro é avaliar a performance institucional dos municípios por meio da elaboração de um indicador de desenvolvimento institucional; o segundo é compreender o impacto desse indicador sobre o produto interno bruto per capita municipal. Para tanto, uma combinação de técnica de análise multivariada e de Mínimos Quadrados em Dois Estágios (MO2E) para a estimação do Spatial Durbin Model (SDM) é utilizada. Os resultados sugerem que o indicador tem efeito positivo sobre o nível do PIB per capita dos municípios brasileiros.

\section{Palavras-Chave}

Instituições. Crescimento. Municípios.

\begin{abstract}
In the face of regional socioeconomic disparities in Brazil and theories that defend the role of institutions in economic development, the present study contemplates two complementary aims. The first is to evaluate the institutional performance of municipalities through the elaboration of an indicator of institutional development; the second is to understand the impact of this indicator on the per capita municipal gross domestic product. To do so, a combination

- Os autores agradecem à FAPEMIG, PROPP/UFJF, Econúcleo/UFJF-GV e Cedeplar/UFMG pelo apoio.

1 Mestrando - Universidade Federal de Juiz de Fora - Departamento de Economia. End.: Campus Universitário - Martelos - CEP: 36001-970 - Juiz de Fora/MG - Brasil - E-mail: lucasleaoff@gmail.com. ORCID: https://orcid.org/0000-0002-9836-7673.

2 Professor - Universidade Federal de Juiz de Fora - Departamento de Economia - Campus Governador Valadares - End.: Av. Doutor Raimundo Monteiro Rezende - Centro - CEP: 35010-177 Governador Valadares/MG - Brasil - E-mail: hilton.manoel@ufjf.edu.br. - URL: https://www.ufjf. br/econucleogv/- ORCID: https://orcid.org/0000-0003-2729-9674.

3 Professora - Universidade Federal de Juiz de Fora - Departamento de Economia. End.: Campus Universitário - Martelos - CEP: 36001-970 - Juiz de Fora/MG - Brasil - E-mail: quinet.bastos@ufjf.edu.br. ORCID: https://orcid.org/0000-0002-8080-1486.

4 Professora - Universidade Federal de Minas Gerais - Departamento de Economia - End.: Avenida Antônio Carlos, 6627 - Pampulha - CEP: 31270-901 - Belo Horizonte/MG - Brasil E-mail: ahermeto@cedeplar.ufmg.br. - ORCID: https://orcid.org/0000-0001-8331-1928. Recebido: 29/05/2018. Aceito: 05/07/2020 Editor responsável: Raul da Mota Silveira Neto
\end{abstract}

(c) (i) (s) Esta obra está licenciada com uma Licença Creative Commons Atribuição-Não Comercial 4.0 Internacional. 
of multivariate techniques analysis and Two-Stage Least Squares (2SLS) to estimate the Spatial Durbin Model (SDM) is used. The results suggest that the indicator has a positive effect on the per capita GDP level of the Brazilian municipalities.

\section{Keywords}

Institutions. Growth. Municipalities.

\section{JEL Classification}

C36. C38. 043.

\section{Introdução}

O contraste entre o nível de desenvolvimento econômico das regiões suscita debates na literatura econômica. Diferentes vertentes buscam por uma teorização que seja capaz de responder por qual motivo algumas economias crescem mais do que outras e, mais do que isso, porque esse comportamento perdura no tempo. Dentre essas vertentes, destaca-se a Economia Institucionalista, que atribui as dessemelhanças observadas nas economias aos seus respectivos aspectos institucionais. North (1990) define as instituições como formuladoras de uma estrutura de incentivos da sociedade, que promovem, a médio e longo prazos, o desenvolvimento econômico das regiões.

No Brasil, com a Constituição Federal de 1988, foram atribuídas maiores competências tanto políticas quanto administrativas aos municípios (Keinert et al. 2006). Estes entes subnacionais adquiriram, segundo Silva (2012), a capacidade de autogoverno, de autoadministração, de auto-organização e de criação de legislação própria. Essas atribuições, atreladas às consequências financeiras do sistema de governo federalista (descentralizador), relacionam-se com a notável desigualdade regional existente no território nacional, assim como observada por Santana e Barreto (2016). Isso levanta a hipótese da existência de heterogeneidade institucional entre os municípios brasileiros. Ou seja, as diversidades intermunicipais, além de estarem relacionadas às questões socioeconômicas, podem estar relacionadas aos diferentes arranjos institucionais presentes em cada um desses entes. Assim, o presente estudo tem o objetivo de elaborar e analisar um indicador institucional multidimensional, a partir da ação do Estado (instituições formais), representada aqui pela análise da gestão pública municipal. Além disso, pretende compreender a relação desse indicador com o nível de crescimento dos municípios brasileiros. 
A justificativa para a criação do instrumento se baseia na escassez de um indicador institucional para municípios e na oferta de um índice composto a partir de técnicas de análise multivariada. Ademais, uma análise espacial do indicador faz-se necessária na medida em que o arranjo institucional de cada município pode ser afetado pelos aspectos institucionais de sua vizinhança. Espera-se que o instrumento seja relevante para explicar as disparidades econômicas regionais no território brasileiro. Para tanto, o trabalho propõe um modelo econométrico que relaciona o indicador com o produto interno bruto (PIB) per capita dos municípios.

A construção do Indicador de Desenvolvimento Institucional Municipal IDIM e a sua avaliação como um instrumento de qualidade institucional estimulam o debate acerca do papel do Estado enquanto ente regulador e promotor de uma atmosfera mais (ou até menos) favorável ao crescimento econômico. Ademais, o perfil multidimensional do índice, contemplando áreas até então não tratadas no indicador institucional criado pelo Ministério do Planejamento para os municípios brasileiros, pode representar um aspecto útil aos formuladores de políticas públicas, na direção de orientá-los sobre as características e qualidade dos seus respectivos arranjos institucionais.

O trabalho está dividido em seis seções, incluindo esta introdução. A segunda seção trata o papel dos municípios na formulação de seus arranjos institucionais. A terceira seção discute a relação entre instituições, crescimento econômico e o papel do Estado como ente promotor de ambientes institucionais capazes de promover o crescimento econômico e apresenta alguns estudos empíricos para o Brasil. A quarta compõe os dados utilizados e os aspectos metodológicos empregados para a construção e avaliação do indicador. A seção cinco apresenta e discute os resultados obtidos e a seção seis traz as considerações finais.

\section{Instituições e municipalização no Brasil}

A Constituição Federal de 1988 proporcionou, dentre outras coisas, um fortalecimento dos entes subnacionais, especialmente os municípios. A eles foram atribuídas maiores competências tanto políticas quanto administrativas (Keinert et al. 2006). Ferreira (2004) denomina tal movimento por Municipalização, a qual apresenta uma vantagem em sua composição, dado a proximidade entre o gestor e o cidadão, o que permite uma melhor cap- 
tação das preferências da sociedade (Silva 2006). Mais especificamente, como ressaltado por Silva (2012), a predominância do interesse é o princípio geral que norteia a repartição de competência entre as entidades do Estado Federal. Nesta divisão cabem à União as matérias e questões de interesse nacional; aos Estados cabem os assuntos de interesse regional; e aos municípios, os de interesse local.

A Municipalização permitiu que tais entes subnacionais obtivessem autonomia e competência para legislar em assuntos de interesse local. Tal autonomia se sustenta em quatro capacidades: de autogoverno, de auto-organização, de autoadministração e a capacidade normativa própria (Silva 2012). De acordo com Senem e Teza (2015), as limitações administrativas do município são provenientes de algumas normas, como a Lei Orgânica, o Plano Diretor, o Código de Obras e Edificações, o Código de Posturas dentre outros, incluindo também as leis específicas. Segundo Linhares (2012), a Constituição estabeleceu algumas diretrizes que permitem que o desenho institucional se encontre em constante transformação, motivadas por interesses cooperativos ou competitivos. Nessa linha, Abrucio e Laczynski (2013) apontam que, embora a autonomia municipal carregue pontos positivos, existem desvantagens atreladas às dificuldades políticas, financeiras e administrativas. Somam-se a isso as intempéries inerentes ao modelo de governo federalista brasileiro, que Linhares (2012) define como sendo cheio de tensões, conflitos e dilemas sobre os modelos de centralização/ descentralização do Estado ao longo de sua história.

Além da descentralização financeira e da baixa capacidade técnica e institucional dos municípios brasileiros, principalmente os de menor porte, outro desafio que a gestão territorial enfrenta é relacionado às relações intergovernamentais (Baldissera 2015). A federação brasileira precisa, de acordo com Silva (2006), buscar um maior equilíbrio entre autonomia e cooperação. Nesse sentido, Anderson (2009) diz que devem ser implementados instrumentos formais de coordenação e cooperação, dado o elevado número de relações intergovernamentais possíveis. Dessa discussão emergem os Consórcios Públicos Intermunicipais, ${ }^{1}$ que têm sido um tema explorado na literatura que busca captar as relações horizontais existentes entre tais entes subnacionais (Alves 2006, Abrucio e Laczynski 2013, Baldissera 2015).

1 O objetivo para a emersão dos Consórcios Públicos Intermunicipais é a prestação de algum serviço público de forma conjunta em função dos interesses da coletividade de municípios participantes (Pereira e Moreira 2016). Os consórcios se colocam como um instrumento relevante de cooperação na gestão intergovernamental que visa fortalecer os entes federados com reduzida capacidade administrativa, gerencial e financeira, principalmente os pequenos municípios (CNM 2016). 


\section{Instituições e crescimento econômico}

Instituições podem ser contratos - ou regras - humanamente desenvolvidos para moldarem a interação dos agentes em uma sociedade. Como uma extensão a esse conceito, North (1990) divide as instituições em formais, que abrangem basicamente legislação; e informais, que são as regras consolidadas pelo convívio social e cristalizadas pelo hábito.

A vertente institucionalista tem se destacado pela busca em apresentar uma relação causal entre crescimento e instituições. Para Acemoglu et al. (2005), estas são determinantes do crescimento econômico de longo prazo, à medida que criam um sistema de incentivos sobre os agentes, influenciando as decisões de investimento e a organização da produção. Tal crescimento econômico é visto por Conceição (2002) como um processo que é articulado no tempo e espaço de acordo com a definição da matriz institucional. Esta, por sua vez, é fruto, segundo Santana e Barreto (2016), das ações de entidades econômicas e organizações empresariais que buscam um arranjo mais propício para aumentarem suas riquezas. Adicionalmente, Acemoglu et al. (2005) apontam que tal matriz parte das escolhas coletivas da sociedade, de acordo com os resultados econômicos proporcionados, e que essas decisões são condicionadas pelo poder político dos diferentes grupos. Dessa forma, diferentes regiões com diferentes interesses econômicos e sociais (privados e coletivos) tendem a apresentar diferentes matrizes institucionais e, consequentemente, distintos níveis de desempenho econômico. Entretanto, sendo a ação estatal uma delimitadora de desenhos institucionais que promovam a cooperação, bem-estar social e crescimento econômico, destaca-se a sua importância sobre as desigualdades regionais. Chang (2003) demonstra mais especificamente os papéis que o Estado deve executar como promotor e garantidor do desenvolvimento econômico, a saber: o de gestor de conflitos, referente à atuação do governo na redução dos custos de transação; e o de empreendedor, que se refere ao aparato que o ente supremo deve dar aos agentes privados, fornecendo-lhes a visão dos objetivos do desenvolvimento econômico futuro e as instituições necessárias para alcançá-lo.

Naritomi (2007) chama a atenção para a possibilidade da existência de uma causalidade reversa entre as grandezas, ou seja, que uma economia mais desenvolvida sustente uma matriz institucional melhor. Para analisar essa questão têm sido consideradas, na literatura institucional empírica, algumas medidas de qualidade institucional (índices de democracia, buro- 
cracia e corrupção) e/ou variáveis instrumentais exógenas (determinantes geográficos, climáticos ou históricos) (Pande e Udry 2005).

Enquanto a teoria econômica convencional (Lucas 1988, Mankiw et al. 1992, Barro e Sala-I-Martin 1995) aponta o crescimento econômico como resultante do processo de acumulação de capital, elevação de capital humano e inovações tecnológicas, os autores institucionalistas defendem que as instituições possuem papel relevante na determinação do desempenho econômico das regiões.

Para North e Thomas (1973), essas variáveis apontadas pela teoria convencional são o próprio crescimento econômico e não a causa deste. De acordo com Acemoglu e Robinson (2008), as diferenças no capital humano, físico e na tecnologia respondem apenas as causas imediatas das disparidades na renda per capita das sociedades, enquanto que o questionamento a ser respondido é porque algumas nações têm menos capital físico, humano e tecnologia e porque fazem um pior uso dos seus fatores de produção e oportunidades.

Acemoglu et al. (2002) apontam a geografia como o principal determinante do crescimento econômico de longo prazo. Assim, o clima, a geografia e a ecologia determinariam as oportunidades econômicas, responsáveis pela obtenção de melhores rendas. Marshall (1890) enfatiza a relevância do clima sobre a força de trabalho e a produtividade, de forma que as regiões mais próximas da linha do Equador tenderiam a apresentar uma relação inversa com o crescimento econômico. Este resultado também é reportado por Acemoglu et al. (2005), que encontram uma relação positiva entre a renda dos países e a distância da linha do Equador. Sachs (2000), por sua vez, aponta não só a importância da geografia, mas também do custo de transporte e da tecnologia.

Atrelando os aspectos geográficos à visão institucionalista, para Engerman e Sokoloff (2002) fatores geográficos podem estar associados às instituições e ao desempenho econômico de forma direta e indireta, quer seja influenciando o tipo de instituições que evoluíram historicamente e impactam o crescimento econômico atual, quer seja afetando diretamente a economia, o que por sua vez também impacta na qualidade das instituições. Os autores, ao considerarem os determinantes históricos e geográficos dos países, observam o impacto exercido sobre os aspectos institucionais e concluem que as instituições não devem ser presumidas como exógenas em relação ao crescimento. 
Rodrik et al. (2004), realizando uma comparação entre as instituições, geografia e o comércio na determinação dos níveis de renda entre os países, demonstram que a qualidade institucional supera as demais variáveis na determinação do crescimento econômico. Observam que, controlado pelas instituições, as medidas convencionais de geografia - clima, latitude, altitude, precipitação pluviométrica, aspectos ecológicos - representam, na melhor das hipóteses, efeitos diretos fracos sobre os rendimentos, embora tenham um forte efeito indireto ao influenciarem a qualidade das instituições. Resultado análogo foi encontrado por Easterly e Levine (2002), ao compararem os determinantes institucionais e geográficos dos países sobre o nível de renda.

Acemoglu et al. (2005) desempenham esforço em demonstrar que as instituições, mais do que a geografia ou os elementos da cultura, são a causa das diferenças de desempenho econômico das nações. Relacionam o produto interno bruto (PIB) per capita dos países e uma medida de direitos de propriedade - indicador fornecido pelos avaliadores de risco-país a potenciais investidores estrangeiros - e demonstram que países com instituições melhores têm melhores PIB per capita.

Nessa mesma linha, Alcalá e Ciccone (2004) consideram um indicador de qualidade institucional que contempla diversas áreas, como: eficiência burocrática do governo; criminalidade; sistema jurídico; execução de contratos e garantia de direitos de propriedade; e aspectos associados a práticas corruptivas. Os autores demonstram que o indicador institucional, controlado por variáveis exógenas, relaciona-se positivamente com a produtividade da mão de obra e com a melhora do desempenho econômico dos países no longo prazo.

\subsection{Evidências empíricas para o Brasil}

Ao realizarem um estudo empírico para os municípios brasileiros, Neto e Nakabashi (2011) e Neto et al. (2014), utilizando o Índice de Qualidade Institucional Municipal (IQIM), ${ }^{2}$ analisaram os impactos das instituições

2 Índice proposto pelo Ministério do Planejamento, Orçamento e Gestão (MPOG), para o Brasil. Construído a partir de dados do ano de 2000. O peso de cada dimensão que forma o indicador foi dado de forma igualitária, diferente do proposto no presente trabalho. Mais detalhes em Ministério do Planejamento, Orçamento e Gestão (2015). 
e do capital humano no investimento líquido e no capital físico por traba1ho, respectivamente. Considerando a latitude, precipitação pluviométrica média anual, temperatura média anual e altitude como variáveis de controle para o IQIM, concluem que o nível de capital humano e a qualidade institucional se relacionam positivamente com o investimento e o nível de capital físico, uma vez que municípios com maiores níveis de capital humano e melhores arranjos institucionais tendem a ter um produto marginal do capital físico maior, juntamente com uma maior segurança no retorno do investimento.

Pereira, Nakabashi e Sachsida (2011), também utilizando o indicador institucional IQIM, encontraram que os aspectos institucionais dos municípios brasileiros são significativos para explicarem as disparidades observadas em seus produtos per capita. Santana e Barreto (2016), além de utilizarem o IQIM, dão uma contribuição à literatura ao atualizá-lo, com os dados de 2010. Desta forma, os autores são capazes de não só detectarem o impacto das instituições para o crescimento econômico como também identificar se houve transformação institucional nos municípios, e qual o impacto deste movimento para seus produtos. Concluíram que a influência da qualidade institucional sobre a renda é positiva e significativa.

Leivas et al. (2015) verificam a importância da dependência espacial para o desempenho econômico dos municípios brasileiros. Utilizando o modelo espacial de Durbin ${ }^{3}$ e considerando o período de 2000 a 2010, demonstraram que a qualidade institucional - medida pelo IQIM - dos vizinhos influencia o desempenho econômico dos municípios. Cidades que têm vizinhos com alta qualidade institucional são afetadas negativamente no curto prazo, o que os autores sugerem estar relacionado ao fato de os municípios com melhores instituições atraírem naturalmente mais investimentos. Apesar deste efeito no curto prazo, salientam que no longo prazo pode haver efeitos spillovers, uma vez que as instituições melhores podem ajudar a fortalecer aquelas com qualidade inferior (a dos vizinhos) no longo prazo. O estudo chama atenção para a importância que o planejamento institucional dos municípios e regiões tem sobre suas dinâmicas econômicas, além de sugerir que deve haver uma atualização dos indicadores que mensuram a qualidade das instituições. Nesse sentido, a proposta do presente estudo vai ao encontro dessa demanda por um novo indicador e de sua análise com o desempenho econômico das regiões.

3 Spatial Durbin Model (SDM). Ver Leivas et al. (2015). 


\section{Base de dados e estratégia empírica}

\subsection{Base de dados}

Para a construção do indicador IDIM, as variáveis utilizadas foram extraídas da Pesquisa de Informações Básicas Municipais (MUNIC), as quais contemplam informações sobre a estrutura, a dinâmica e o funcionamento das instituições públicas municipais. Estes dados são fornecidos pelo Instituto Brasileiro de Geografia e Estatística (IBGE), captados para os anos de 2013, 2014 e 2015. Busca-se trabalhar com um horizonte temporal composto por esses três anos mais recentes por três motivos: o primeiro se deve a mudanças nos questionários da MUNIC ao longo dos anos, de modo que existe uma relativa descontinuidade das variáveis em cada ano de uma mesma gestão municipal; o segundo é que, ao se trabalhar com mais de um ano, torna-se possível agregar um maior número de diferentes variáveis; e terceiro, as instituições formais tendem a não sofrer grandes variações no curto prazo, principalmente dentro de um mesmo período de gestão municipal. A seleção de variáveis abrange 27 variáveis, contemplando 5.561 municípios. A análise descritiva dos dados pode ser visualizada na Tabela 1.

A escolha das variáveis para a composição do indicador baseia-se nas atribuições normativas dadas aos municípios após o processo de municipalização, proporcionado pela Constituição Federal de 1988 (Senem e Teza 2015). Ademais, incorporam-se as variáveis relativas aos Consórcios Públicos ${ }^{4}$ em suas diversas áreas de atuação. Isso reflete a relevância da discussão da gestão intergovernamental horizontal, principalmente diante dos obstáculos enfrentados pelo sistema federativo descentralizado experimentado no Brasil (Alves 2006, Anderson 2009, Baldissera 2015).

4 De acordo com Baldissera (2015), a Lei 11.107/2005, conhecida como Lei dos Consórcios, representa um marco na relação intergovernamental representada por meio de consórcios públicos no Brasil. Com a sua promulgação, os consórcios constituídos até então, que possuíam um caráter administrativo, passaram a ter respaldo jurídico, o que representou uma maior segurança aos entes consorciados. 
Tabela 1 - Descrição das variáveis para construção do indicador institucional - IDIM

\begin{tabular}{|c|c|c|c|c|c|}
\hline \multirow{2}{*}{ Vars } & \multirow{2}{*}{ Descrição } & \multicolumn{2}{|c|}{ Sim } & \multicolumn{2}{|c|}{ Não } \\
\hline & & Freq. & $\%$ & Freq. & $\%$ \\
\hline A1 & $\begin{array}{l}\text { Legislação sobre solo criado ou outorga onerosa do direito de construir - exis- } \\
\text { tência }\end{array}$ & 1946 & $35 \%$ & 3623 & $65 \%$ \\
\hline A2 & Plano diretor - existência & 2785 & $50 \%$ & 2781 & $50 \%$ \\
\hline A3 & Legislação sobre zona e/ou área de interesse social - existência & 2476 & $44 \%$ & 3091 & $56 \%$ \\
\hline A4 & Legislação sobre zona e/ou área de interesse especial - existência & 2065 & $37 \%$ & 3502 & $63 \%$ \\
\hline A5 & Legislação sobre parcelamento do solo - existência & 3125 & $56 \%$ & 2442 & $44 \%$ \\
\hline A6 & Legislação sobre zoneamento ou uso e ocupação do solo - existência & 3021 & $54 \%$ & 2546 & $46 \%$ \\
\hline A7 & Legislação sobre solo criado - existência & 1295 & $23 \%$ & 4272 & $77 \%$ \\
\hline A8 & Legislação sobre operação urbana consorciada - existência & 1036 & $19 \%$ & 4531 & $81 \%$ \\
\hline A9 & Legislação sobre estudo de impacto de vizinhança - existência & 1495 & $27 \%$ & 4073 & $73 \%$ \\
\hline A10 & Código de obras - existência & 3475 & $62 \%$ & 2093 & $38 \%$ \\
\hline A11 & Consórcio Público na área de Educação & 374 & $7 \%$ & 5193 & $93 \%$ \\
\hline A12 & Consórcio Público na área de Assistência e desenvolvimento social & 463 & $8 \%$ & 5104 & $92 \%$ \\
\hline A13 & Consórcio Público na área de Turismo & 485 & $9 \%$ & 5082 & $91 \%$ \\
\hline A14 & Consórcio Público na área de Cultura & 358 & $6 \%$ & 5209 & $94 \%$ \\
\hline A15 & Consórcio Público na área de Habitação & 281 & $5 \%$ & 5286 & $95 \%$ \\
\hline A16 & Consórcio Público na área de Meio ambiente & 929 & $17 \%$ & 4638 & $83 \%$ \\
\hline A17 & Consórcio Público na área de Transporte & 351 & $6 \%$ & 5216 & $94 \%$ \\
\hline A18 & Consórcio Público na área de Desenvolvimento urbano & 724 & $13 \%$ & 4843 & $87 \%$ \\
\hline A19 & Consórcio Público na área de Saneamento básico & 691 & $12 \%$ & 4876 & $88 \%$ \\
\hline A20 & Consórcio Público na área de Gestão das águas & 427 & $8 \%$ & 5140 & $92 \%$ \\
\hline A21 & Lei municipal que institui Plano Municipal de Direitos Humanos & 48 & $1 \%$ & 5519 & $99 \%$ \\
\hline A22 & $\begin{array}{l}\text { Lei de Plano Municipal de Enfrentamento à Violência Sexual contra Crianças e } \\
\text { Adolescentes }\end{array}$ & 205 & $4 \%$ & 5362 & $96 \%$ \\
\hline A23 & $\begin{array}{l}\text { Lei municipal que institui Plano Municipal de Enfrentamento à Violência contra a } \\
\text { Mulher }\end{array}$ & 143 & $3 \%$ & 5424 & $97 \%$ \\
\hline A24 & Lei municipal que institui Plano Municipal de Atendimento Socioeducativo & 142 & $3 \%$ & 5425 & $97 \%$ \\
\hline A25 & $\begin{array}{l}\text { Lei de Plano de Promoção do Direito de Crianças e Adolescentes à Convivência } \\
\text { Familiar e Comunitária }\end{array}$ & 419 & $8 \%$ & 5148 & $92 \%$ \\
\hline A26 & Lei municipal que institui Plano Municipal de Proteção Integral à Primeira Infância & 96 & $2 \%$ & 5471 & $98 \%$ \\
\hline A27 & Lei específica em aspectos da área de Direitos Humanos & 520 & $9 \%$ & 5047 & $91 \%$ \\
\hline
\end{tabular}

Nota: Frequências de variáveis em branco não são consideradas.

Fonte: Elaboração dos autores, a partir da MUNIC (2013/2014/2015).

De acordo com Senem e Teza (2015), as limitações administrativas do município são provenientes de algumas normas, como a Lei Orgânica, o Plano Diretor, o Código de Obras e Edificações, o Código de Posturas etc., incluindo também as leis específicas. 
Já para a análise da relação entre o crescimento econômico municipal e o desempenho institucional medido pelo IDIM, os dados utilizados são: despesa de capital; o PIB per capita; uma variável contínua criada a partir do indicador de complexidade da gestão das escolas, ${ }^{5}$ em termos per capita, denominada "número de escolas com complexidade média"; a estimativa média trimestral de precipitações pluviométricas nos municípios; as estimativas das médias trimestrais municipais de temperatura e a latitude dos municípios. A despesa de capital é proxy para o estoque de capital físico; ${ }^{6}$ o PIB per capita representa o nível de renda dos municípios; o número de escolas com complexidade média é proxy para o capital humano; ${ }^{7}$ e as variáveis geográficas compreendem o vetor de controles exógenos considerado no sistema de equações simultâneas. A análise descritiva dos dados pode ser visualizada Tabela 2 .

Tabela 2 - Descrição das variáveis para análise de crescimento - 2014

\begin{tabular}{lcccc}
\hline Variável & Obs & Média & Des.Padrão & Fonte \\
\hline PIB per capita & 5.570 & 18647,92 & 21188,750 & IBGE \\
Despesa de capital para investimento per capita & 5.182 & 238,641 & 222,086 & Tesouro Nacional \\
Número de escolas com complexidade média & 5.570 & 13,015 & 11,665 & INEP (2014) \\
Temperatura média (anual) $^{1 .}$ & 4.974 & 22,731 & 2,987 & IPEA (2014) \\
Precipitação pluviométrica média (anual) & 4.974 & 116,108 & 36,63 & IPEA (2014) \\
Latitude $^{5.507}$ & $-16,397$ & 8,266 & IBGE \\
\hline
\end{tabular}

1. Baseado em New et al. (2002). Os valores trimestres médios foram somados e divididos por quatro, para a obtenção de um valor médio anual das precipitações pluviométricas e da temperatura média, por município.

Fonte: Elaboração dos autores, a partir dos dados do IBGE (2014), Tesouro Nacional (2014), Atlas do Desenvolvimento Humano (2010), INEP (2014) e IPEA (2014).

5 Criado pelo Ministério da Educação, o indicador para mensurar a complexidade da gestão nas escolas no ano de 2015 se baseia no Censo Escolar da Educação Básica de 2014. Divide-se hierarquicamente em 6 níveis, cujo primeiro nível representa o percentual de escolas de cada município consideradas menos complexas e o sexto, o das escolas mais complexas. Uma vez que os níveis 3 e 4 representam os níveis intermediários e compreendem, juntas, cerca de $44 \%$ do número total de matrículas no Brasil, optou-se por extrair o número de escolas, pertencentes a cada município, a partir das informações dos percentuais do índice de complexidade para as categorias 3 e 4 e do número total de cada município, obtido no Censo Escolar de 2013. O nível 3 representa as escolas com porte entre 50 e 500 matrículas, operando em 2 ou 3 turnos, com 2 ou 3 etapas e apresentando os Anos Finais como etapa mais elevada. O nível 4 equivale às escolas com porte entre 500 e 1000 matrículas, operando em 2 ou 3 turnos, com 2 ou 3 etapas, apresentando Ensino Médio/profissional ou a EJA como etapa mais elevada. Para mais detalhes, ver Ministério da Educação (2013).

6 Normalmente, a literatura utiliza o consumo de energia elétrica e/ou o estoque de capital físico residencial para representar o estoque de capital físico. No entanto, dada a dificuldade na obtenção desses dados para os municípios brasileiros no período analisado, buscou-se instrumentos alternativos.

7 A escolha dessa variável se dá pela dificuldade na obtenção da proxy que geralmente é utilizada pela literatura (não há, também, a disponibilidade de dados recentes para essa variável), a saber: a própria variável intitulada "capital humano". 
Baseado em Kroth e Dias (2012), o estoque de capital físico é retratado pelo investimento público, que se materializa por meio das despesas de capital per capita do município. Os autores propõem a segmentação do capital físico em público e privado. O investimento público reflete a formação de uma infraestrutura básica no município e o investimento privado, a ampliação da capacidade produtiva. Este último é caracterizado, pelos autores, através do crédito bancário voltado para o investimento. Mas, dada a quantia elevada de dados faltantes para essa variável no período analisado, consideram-se apenas os dados que se referem ao investimento dos governos, através da variável de despesa de capital per capita.

O capital humano é tido como um fator relevante para o desempenho econômico, uma vez que afeta diretamente as habilidades do trabalhador, tornando-o mais produtivo. Assim, o estoque de capital humano contempla como proxy o número de escolas com complexidade média, extraída do indicador de complexidade da gestão nas escolas, criado pelo Ministério da Educação. Alves e Soares (2013) indicam que escolas mais complexas têm maiores dificuldades de atingirem melhores resultados educacionais. Por outro lado, municípios muito pequenos e/ou pouco desenvolvidos são caracterizados pela existência de escolas menos complexas ou até mesmo a falta de escolas. Diante disso, e da observação de que a maior proporção do total de matrículas no Brasil é originária de escolas com complexidade média, optou-se pela utilização de uma variável contínua que contabiliza o número total de escolas com complexidade média em cada um dos municípios como proxy para o estoque de capital humano.

No que se refere aos métodos, a criação do indicador institucional parte da Análise Fatorial, enquanto sua avaliação espacial depende da Análise Exploratória de Dados Espaciais (AEDE). Para a análise da relação entre as dimensões econômica e institucional dos municípios realiza-se a estimação do Spatial Durbin Model (SDM). ${ }^{8}$

\subsection{Análise fatorial}

As técnicas exploratórias de análise fatorial são aplicáveis a bases de dados compostas por variáveis que possuem, entre si, coeficientes de correlação relativamente elevados, de modo que seja possível o estabelecimento de

8 Ver Anselin (2013). 
novas variáveis - fatores - que captem o comportamento conjunto das variáveis originais. Essa técnica faz uso do coeficiente de correlação entre as variáveis para agrupá-las e gerar fatores. A medida de associação mais utilizada é o Coeficiente de Correlação amostral de Pearson, ${ }^{9}$ para variáveis contínuas. Para o caso das variáveis de natureza dicotômica, como é o caso das variáveis da MUNIC, sugere-se a utilização da matriz de correlação tetracórica. ${ }^{10}$

Após a construção da matriz de correlações, inicia-se o procedimento para a determinação dos fatores através da Análise Fatorial. O método utilizado é o de Componentes Principais, que permite a extração de fatores não correlacionados a partir de combinações lineares das variáveis originais. A escolha deste método se deve a não exigência de pressupostos iniciais, como, por exemplo, o de uma distribuição normal das variáveis (Mingoti 2007). O critério para a escolha ótima de fatores a serem gerados a partir do conjunto de variáveis originais é o da raiz latente. Para facilitar a interpretação dos fatores gerados é realizada uma rotação ortogonal pelo método varimax, ${ }^{11}$ que procura minimizar o número de variáveis que têm uma correlação forte com cada fator, permitindo a obtenção de "fatores mais facilmente interpretáveis" (De Melo e Parré 2012, 17).

Para que seja verificada a adequação global da extração dos fatores, deve-se recorrer à estatística Kaiser-Meyer-Olkin (KMO) ${ }^{12}$ e ao teste de esfericidade de Bartlett. ${ }^{13}$ A estatística KMO fornece a proporção da variância considerada comum a todas as variáveis, variando de 0 a 1 . Valores mais próximos de 1 indicam que as variáveis compartilham um elevado percentual de variância, enquanto os valores mais próximos de 0 decorrem de baixas correlações entre as variáveis, podendo indicar que a análise fatorial será inadequada. Já o teste de esfericidade de Bartlett realiza uma comparação entre a matriz de correlações e uma matriz identidade de mesma dimensão. Se as diferenças entre os valores correspondentes fora da diagonal principal de cada matriz não forem estatisticamente diferentes de 0 , a

9 Consultar Benesty et al. (2009).

${ }^{10} \mathrm{O}$ Coeficiente de Correlação Tetracórico é uma estimativa do Coeficiente de Correlação Linear de Pearson. No entanto, a correlação é medida entre duas variáveis "latentes", e , ou seja, duas variáveis "virtuais" que surgiram a partir das variáveis dicotômicas observadas, X e Y. Essas novas variáveis são contínuas e normais (Lira 2004). De acordo com Guilford (1950), o Coeficiente de Correlação Tetracórico é menos confiável que o Coeficiente de Pearson, com variabilidade $50 \%$ maior quando a correlação é igual a zero. Para obter a mesma confiabilidade (em termos de desvio-padrão), é recomendada a utilização de amostras com mais de 300 observações.

11 Ver Kaiser (1958).

12 Apresentada inicialmente por Kaiser (1970).

13 Ver Bartlett (1954). 
determinado nível de significância, pode-se considerar que a extração dos fatores não será adequada (Fávero e Belfiore 2015).

A consistência interna das variáveis de um banco de dados pode ser avaliada através da estatística alpha, proposta por Cronbach (1951). Esta demonstra a fidedignidade com a qual o fator pode ser extraído a partir das variáveis, sendo, portanto, uma estatística única para cada fator. É indicado que o resultado da estatística alpha seja maior do que 0,6 na aplicação das técnicas exploratórias (Fávero e Belfiore 2015). Isto posto, o índice obtido é dado por (1):

$$
\operatorname{IDIM}_{i}=\sum_{j=1}^{k} \frac{\lambda_{j}}{\operatorname{tr}(\rho)} F_{j}
$$

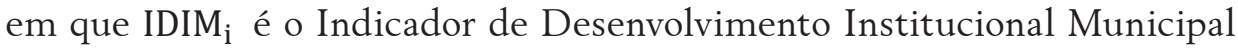
para o município $i$; $\lambda_{j}$ é a j-ésima raiz característica da matriz de correlações $\rho$; $\mathrm{k}$ é o número de fatores escolhidos; $\mathrm{F}_{\mathrm{ij}}$ é a carga fatorial do município i, do fator j; tr é o traço da matriz de correlação $\rho$. Assim, $\frac{\lambda_{j}}{\operatorname{tr}(\rho)}$ representa a variância compartilhada, ou seja, indica o peso relativo de cada fator na variância total dos dados.

\subsection{Análise Exploratória de Dados Espaciais - AEDE}

De acordo com a lei de Tobler, todas as coisas são relacionadas, mas as coisas mais próximas são mais relacionadas do que as mais distantes (Tobler 1970). Pode-se dizer que esta é uma das características que define o conceito estatístico de autocorrelação espacial. Assim, o arranjo institucional do município poderia influenciar (e ser influenciado) por seus municípios vizinhos. Isto posto, emprega-se o a AEDE com o intento de captar o padrão espacial dos municípios brasileiros no que tange a seus arranjos institucionais.

A autocorrelação espacial pode ser de caráter global ou local, sendo o primeiro de natureza mais ampla sobre o território, em sua totalidade, e o segundo com enfoque mais específico, ao analisar separadamente as áreas pertencentes ao território. Para a construção de uma estatística de autocor- 
relação espacial, necessita-se de uma medida de autocovariância, uma de variância dos dados e uma matriz de ponderação espacial (Almeida 2012). Esta última representa o grau de conexão entre as regiões segundo algum critério de proximidade, como a contiguidade, por exemplo, e que se tem algumas convenções para a definição das fronteiras. Dentre as medidas de autocorrelação espacial, destaca-se o Índice de associação espacial de Moran.

A estatística global do índice demonstra o grau pelo qual o conjunto dos dados está agrupado, disperso ou aleatoriamente distribuído, considerando a média para todas as regiões. Para detectar o tipo de associação espacial de cada região dentro do território considerado, deve-se recorrer ao índice local. O I de Moran Local faz parte do conjunto de "Local Indicator of Spatial Association (LISA)" ${ }^{14}$, dado por (2):

$$
\mathrm{I}_{\mathrm{i}}=\mathrm{z}_{\mathrm{i}} \sum_{\mathrm{j}=1}^{\mathrm{j}} \mathrm{W}_{\mathrm{ij}} \mathrm{Z}_{\mathrm{j}}
$$

em que $z_{i}$ é a observação padronizada, para o município $i ; w_{i j}$ indica como os municípios $i$ e $j$ são conectadas; e $z_{j}$ é a variável padronizada, observada em $j$.

A estatística I de Moran, tanto local quanto global, é uma espécie de coeficiente de autocorrelação e a hipótese nula sendo testada é a da aleatoriedade espacial. De acordo com Cliff e Ord (1981) apud Almeida (2012), o I de Moran tem um valor esperado, ou seja, aquele que seria obtido caso não houvesse padrão espacial nos dados, de $-[1 /(n-1)]$, ${ }^{15}$ onde $n$ é o número de regiões. Se o valor do índice exceder o valor esperado, há indício de uma autocorrelação espacial positiva, e se o resultado for abaixo do valor esperado, há uma sinalização de autocorrelação negativa.

\subsection{Modelagem econométrica espacial}

Baseado em Hall e Jones (1999), parte-se da função de produção do tipo Cobb-Douglas (3).

\footnotetext{
${ }^{14}$ Além do I de Moran Local, existem, ainda, outras estatísticas do tipo LISA, como o gama local e o c de Geary. Para maiores detalhes, consultar Anselin (1995).

15 Tende a zero quando o número de observações tende ao infinito (Almeida 2012).
} 


$$
Y_{i}=K_{i}^{\alpha}\left(A_{i} H_{i}\right)^{1-\alpha}
$$

onde $K_{i}$ é o estoque de capital físico, $H_{i}$ é o estoque de capital humano aumentado usado na produção e $A_{i}$ é uma medida aumentadora da produtividade do trabalho. Dividindo-se ambos os lados da equação por $L_{i}$ (trabalho, que assumimos como homogêneo dentro de cada município) ${ }^{16} \mathrm{e}$ elevando por $1 /(1-\alpha)$, e utilizando as letras minúsculas para denotarem os valores em termos per capita, obtém-se:

$$
y_{i}=\left(K_{i} / Y_{i}\right)^{(\alpha /(1-\alpha))} \times\left(A_{i} \times h_{i}\right)
$$

onde ; $y \equiv Y / L ; h \equiv H / L$.

Considerando $\bar{K}_{i}=\left(K_{i} / Y_{i}\right)^{(\alpha /(1-\alpha))}$ e $\bar{H}_{i}=\left(A_{i} \times h_{i}\right)$, em termos logarítmicos tem-se:

$$
\ln y_{i}=\ln \bar{K}_{i}+\ln \bar{H}_{i}
$$

A teoria econômica tem buscado encontrar determinantes para o nível de desenvolvimento das regiões para além do estoque de capital físico e humano. Sendo assim, deve-se considerar em (5) um termo de erro, $\epsilon_{i}$, que abarca todos os elementos capazes de explicarem $y$ e que não são considerados nesta forma funcional:

$$
\ln y_{i}=\ln \bar{K}_{i}+\ln \bar{H}_{i}+\epsilon_{i}
$$

Dentre tais teorias tem-se a institucionalista, que defende que os aspectos institucionais, $I_{i}$, devem ser retiradas do termo de erro em (6) e considerados do lado direito da equação. Acrescido de uma constante, $\alpha_{0}$, e dos parâmetros, a especificação econométrica é:

$$
\ln y_{i}=\alpha_{0}+\alpha_{1} \ln \bar{K}_{i}+\alpha_{2} \ln \bar{H}_{i}+\alpha_{3} I_{i}+\varepsilon_{i}
$$

Para lidar com a possível causalidade reversa existente entre o arcabouço institucional dos municípios e suas respectivas performances econômicas, Pereira et al. (2011) sugerem que sejam utilizados instrumentos que são

${ }^{16}$ Partimos do pressuposto de que cada trabalhador recebeu o mesmo estímulo educacional, $E_{i}$, de modo que o capital humano aumentado é dado por: $H_{i}=e^{\theta\left(E_{i}\right)} L_{i}$. 
fontes de variação exógena capazes de captar a influência das instituições no desenvolvimento econômico. De acordo com os autores, os aspectos geográficos físicos, como latitude, precipitação pluviométrica e temperatura média anual são variáveis válidas como instrumentos para as instituições.

Pereira et al. (2012) apontam, a partir da observação do aglomerado de municípios com um nível de desenvolvimento econômico menor e com arcabouços institucionais "piores" nas regiões Norte e Nordeste do Brasil, que as regiões mais próximas à linha do Equador - as de maior temperatura média anual - foram historicamente as mais propícias para o desenvolvimento de culturas agrícolas caracterizadas por uma forte concentração de terras, o que levou à formação de instituições menos favoráveis à geração de oportunidades, impactando negativamente o processo de industrialização e o desenvolvimento econômico de médio e longo prazo. A partir disso, a estratégia empírica empregada para verificar o impacto das instituições na performance econômica dos municípios brasileiros segue Bosker e Garretsen (2009), que consideram a endogeneidade institucional através de um processo de estimação em dois estágios. As variáveis utilizadas para instrumentalizar os aspectos institucionais são a latitude, precipitação pluviométrica e temperatura média anual. As instituições dos vizinhos também são instrumentalizadas, assim como sugerido por esses autores, diante de uma possível causalidade reversa existente entre tal variável e o nível de renda dos municípios. Seguindo Leivas et al. (2015), são adotados os seguintes passos:

$\left.1^{\circ}\right)$ As variáveis geográficas exógenas (latitude, precipitação e temperatura), denotadas por um vetor $Z$, são utilizadas em um primeiro estágio como instrumentos para as instituições:

$$
I_{i}=\theta_{0}+\theta_{1} \ln \bar{K}_{i}+\theta_{2} \ln \bar{H}_{i}+Z \delta+\mu_{i}
$$

$2^{\circ}$ ) Com as instituições estimadas em (8), as instituições estimadas dos vizinhos são construídas, ou seja, $W \hat{I}_{i}$.

Como apontado por Leivas et al. (2015), dever-se-ia realizar uma regressão do produto dos municípios em função de suas instituições estimadas e as instituições estimadas dos vizinhos. No entanto, tal especificação não é eficaz para o controle da endogeneidade espacial para o caso do Brasil. Sendo assim, baseado em Silva e Resende (2009), Barreto et al. (2010) e Firme 
e Filho (2014), que ressaltam a relevância da inclusão da variável do PIB per capita defasada espacialmente ${ }^{17}$ com o intuito de se evitar estimações ineficientes e/ou consistentes para os municípios brasileiros, uma especificação adicional deve ser considerada. Para tanto, o Modelo Espacial de Durbin (Spatial Durbin Model - SDM) ${ }^{18}$ é a especificação mais adequada, uma vez que é capaz de lidar não só com a dependência espacial do nível de renda dos municípios, como também verificar o impacto das instituições dos vizinhos sobre o produto dos entes avaliados.

Portanto, a especificação do modelo SDM - controlada a endogeneidade das instituições em (8) - a ser estimado é:

$$
\begin{aligned}
\ln y_{i}=\vartheta_{0}+ & \gamma\left(W \ln y_{i}\right)+\rho \hat{I}_{i}+\lambda\left(W \hat{I}_{i}\right)+ \\
& \sigma \ln \bar{K}_{i}+\phi\left(W \ln \bar{K}_{i}\right)+\beta \ln \bar{H}_{i}+\pi\left(W \ln \bar{H}_{i}\right)+\eta_{i}
\end{aligned}
$$

onde $\hat{I}_{i}$ e $y_{i}$ representam, respectivamente, o indicador para instituições estimado no primeiro estágio e o PIB per capita dos municípios; $\bar{K}_{i}$ é a variável proxy para o capital físico; $\bar{H}_{i}$ é a proxy para capital humano; $\eta_{i}$ é o termo de erro; e as variáveis precedidas do operador $\mathrm{W}$ denotam as defasagens espaciais das variáveis consideradas.

A variável $W$ representa a matriz de pesos espaciais, que tem seus elementos $w_{i i}$ iguais a zero e os elementos $w_{i j}$ mostram como a região i se conecta à região j. A matriz de ponderação espacial é, na visão de Almeida (2012), uma medida do grau de conexão entre as regiões, podendo ser definida de acordo com o critério geográfico ou socioeconômico. $\mathrm{O}$ autor ressalta o dilema na escolha da melhor matriz de pesos espaciais. A escolha da melhor matriz de pesos espaciais envolve alguns procedimentos, como os de Baumont (2004) e de Stakhovych e Bijmolt (2009), no entanto, o uso da teoria e a análise de sensibilidade ${ }^{19}$ também são alternativas para a escolha da melhor matriz de pesos espaciais a ser usada. ${ }^{20}$ Leivas et al. (2015),

\footnotetext{
${ }^{17}$ Ignorar estruturas de dependência espacial faz com que os estimadores se tornem tendenciosos e inconsistentes (Stakhovych e Bijmolt 2009).

${ }^{18}$ De acordo com LeSage e Fischer (2008), o processo de geração de dados para um modelo SDM se dá a partir da situação em que há a omissão de uma ou mais variáveis relevantes que exibem correlação com a variável incluída na regressão. Ademais, tal variável omitida é espacialmente autocorrelacionada. Sendo assim, o modelo é capaz de decompor os efeitos espaciais de tal variável omitida tanto sobre as variáveis explicativas quanto sobre a dependente.

${ }^{19} \mathrm{O}$ método consiste em estimar o mesmo modelo espacial $\mathrm{n}$ vezes, usando $\mathrm{n}$ matrizes de pesos espaciais diferentes, comparando, ao final, se há discrepâncias nos resultados.

${ }^{20}$ Estudos mais primitivos apontavam para a existência de sensibilidade dos efeitos marginais nos
} 
ao avaliarem a importância da geografia em termos relativos para o desempenho econômico dos municípios brasileiros, sob a discussão institucional, utilizam a matriz de contiguidade Queen, definida de forma ad hoc. Baseado nos autores, considera-se, também, a matriz de contiguidade do tipo Queen no presente estudo.

A estimação do modelo SDM pode ser realizada por meio do Método de Máxima Verossimilhança (MV), que, apesar de ser um método capaz de gerar estimadores com propriedades de eficiência, consistência e normalidade assintótica, requer o cumprimento de alguns pressupostos, como a normalidade e homocedasticidade dos resíduos (LeSage e Pace 2009). Uma alternativa caso não seja observada a normalidade do termo de erro aleatório é o Método de Mínimos Quadrados em Dois Estágios (MQ2E). Utiliza-se como instrumentos as defasagens espaciais das defasagens espaciais (Almeida 2012). Para que a homocedasticidade e normalidade dos resíduos sejam avaliadas são empregados, respectivamente, os testes de Koenker-Bassett (hipótese nula de homocedasticidade) e Jarque-Bera (hipótese nula de normalidade).

Às estimações das Equações (8) e (9) acrescenta-se a variável de controle denominada "borda", que é uma dummy que assume valor 1 caso o município seja fronteiriço (com o litoral ou outros países). De acordo com Almeida (2012), o problema conhecido como efeito de beirada pode ocorrer quando se trabalha com dados espaciais e caracteriza-se pela possível falha na captura total da dependência espacial sob o escopo do fenômeno investigado. Diante disso, e tomando conta da estrutura do indicador de instituições - que abarca elementos de relação intermunicipal (através dos consórcios) -, é relevante a inclusão desse controle nas estimações.

\section{Resultados e discussão}

Este tópico apresenta e discute brevemente os resultados encontrados a partir da criação e análise da relevância do IDIM como elemento capaz de explicar, de certa forma, as particularidades e a diversidade dimensional

modelos de regressão espacial dada a especificação da matriz de contiguidade. No entanto, estudos mais recentes defendem que se as estimativas e inferências forem baseadas nas verdadeiras derivadas parciais de um modelo espacial bem especificado, a escolha da matriz de pesos espaciais não exerce influência considerável sobre os resultados (LeSage e Pace 2014). 
dos arranjos institucionais dos municípios brasileiros. Ao mesmo tempo, avalia a dinâmica espacial dos desenhos institucionais com o intuito de entender melhor, a partir das premissas da teoria institucionalista, as observadas disparidades socioeconômicas regionais no território nacional.

\subsection{O Indicador de Desenvolvimento Institucional Municipal - IDIM}

A partir das 27 variáveis da MUNIC, a Análise Fatorial permitiu a extração de três fatores. Considerando rotação destes pelo método varimax, obtém-se um percentual da variância explicada de 77,80\%. A Tabela 3 indica os fatores formados, a variância compartilhada pelas variáveis originais e a estatística alpha de Cronbach.

Tabela 3 - Fatores, variância compartilhada e alpha de Cronbach

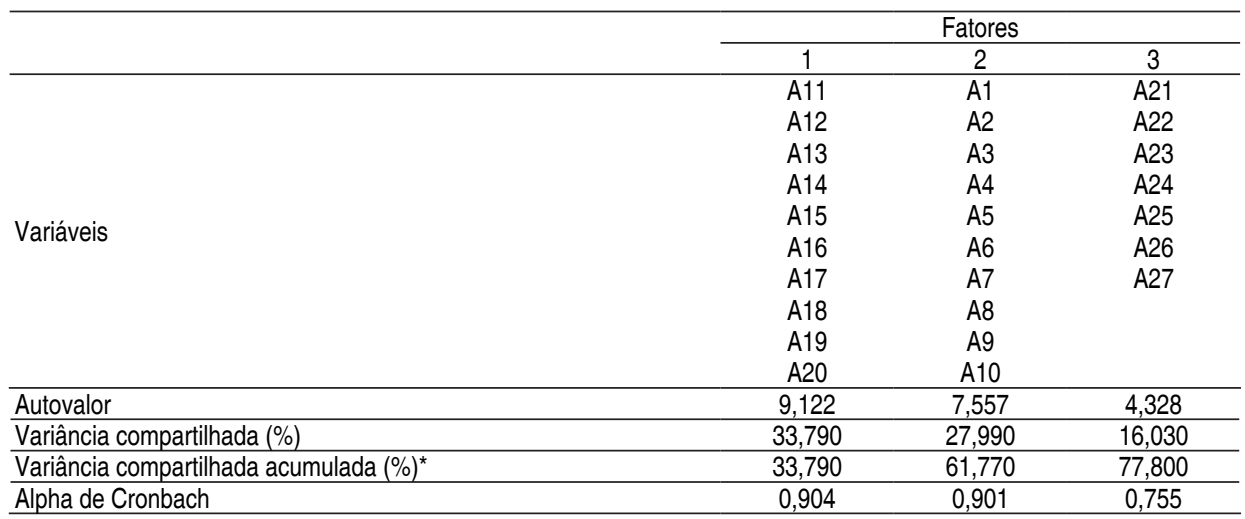

* Indica o total da variância explicada por $n+(n-1)$ fatores.

Fonte: Elaboração dos autores.

Para visualizar a confiabilidade do instrumento, ou seja, se a técnica multivariada de Análise Fatorial é adequada para a base de dados analisada, realizam-se os testes de Kaiser-Meyer-Olkin - KMO e o de esfericidade de Bartlett (Tabela 4).

Tabela 4 - Testes de adequação da amostra

\begin{tabular}{|c|c|c|}
\hline KMO & & 0,902 \\
\hline \multirow{3}{*}{ Esfericidade de Bartlett } & Qui-quadrado aproximado & 72275,512 \\
\hline & Graus de liberdade & 351 \\
\hline & Significância & 0,000 \\
\hline
\end{tabular}

Fonte: Elaboração dos autores. 
De acordo com o teste $\mathrm{KMO}$, as variáveis compartilham um percentual de variância elevado, com um valor de 0,902 , o que pode ser atribuído à existência de um fator comum entre elas, sendo apropriadas para o tipo de análise empregado. O teste de Bartlett também demonstra que a extração de fatores é adequada, com um alto nível de significância. O teste do alpha de Cronbach (Tabela 3) retrata a consistência interna dentro de cada fator extraído, demonstrando que todos os fatores possuem bons resultados (maior que 0,7$) \cdot{ }^{25}$ Os testes de confiabilidade indicam não haver a necessidade de exclusão ou reavaliação de qualquer variável utilizada na Análise Fatorial. Assim, definem-se os fatores (ou subíndices), para 5.561 municípios.

O primeiro fator, que representa o maior percentual da variância compartilhada pelas variáveis originais, é formado pela junção das variáveis relativas aos consórcios públicos, na área de educação, turismo, cultura, transporte, meio ambiente, dentre outros. O subíndice é denominado de "Articulação Inter-regional". De acordo com Cunha (2004), os consórcios públicos surgem como um elemento constitucional que possibilita a criação de meios de coordenação, cooperação e pactuação entre os entes federativos. Assim, dado o mecanismo de promoção à cooperação que é criado por meio de consórcios, ressalta-se a relevância deles como instrumentos relacionados a um arcabouço institucional promotor do crescimento econômico.

O segundo fator é intitulado "Urbano-institucional", o qual contempla variáveis como: legislação sobre parcelamento do solo, legislação sobre solo criado, legislação sobre operação urbana consorciada e legislação sobre estudo de impacto da vizinhança. $\mathrm{O}$ indicador, que incorpora elementos que tratam da legislação sobre o planejamento urbano/regional, está relacionado à questão institucional na medida em que trata de regras e leis sobre organização territorial.

O terceiro fator se forma a partir de variáveis como: legislação que institui plano de direitos humanos, legislação que institui plano de direitos ao enfrentamento à violência contra a mulher, legislação que institui plano de direitos da criança e do adolescente à convivência familiar e comunitária, dentre outras. Por se tratar de variáveis relacionadas a leis que garantem os

${ }^{25}$ De acordo com Fávero e Belfiore (2015), não há na literatura o consenso de um valor mínimo para que o alpha de Cronbach seja aceito como bom, no entanto, como ressaltado por Da Hora et al. (2010), encontram-se indícios de um valor de 0,70 como mínimo aceitável (Urdan 2001, Freitas e Rodrigues 2005, Milan e Trez 2005). Há, ainda, trabalhos que utilizam a medida sem nenhuma menção a um mínimo (Matos e Veiga 2000, Pagan et al. 2012). 
direitos sociais, recebe o nome de "Direitos Humanos". Para Fiani (2002), uma sociedade que discrimina parcela significativa de sua população tende a promover a concentração de poder a grupos privilegiados, o que gera efeitos nocivos ao desenvolvimento, à medida que afasta os retornos privado e social. Ademais, pressupõe-se que a garantia dos direitos humanos tende a auxiliar na manutenção de um ambiente de maior harmonia e cooperação entre os agentes.

Para a construção do Indicador de Desenvolvimento Institucional Municipal (IDIM), é considerado, para cada município, o somatório dos valores dos subíndices, ponderados pelas suas respectivas proporções na variância total. ${ }^{21}$ Os dados da Tabela 5 apresentam a estatística descritiva do indicador.

Tabela 5 - Descrição do indicador

\begin{tabular}{lccc}
\hline Variável & Obs & Média & Desvio Padrão \\
\hline $\begin{array}{l}\text { Índice de Desenvolvimento } \\
\text { Institucional Municipal (IDIM) }\end{array}$ & 5561 & 0,202 & 0,170 \\
\hline
\end{tabular}

Nota: Os valores do índice IDIM foram transformados para uma escala que varia entre 0 e 1 .

Fonte: Elaboração dos autores.

No ranking geral, as cidades de Barueri, Santo André e São Bernardo do Campo, no estado de São Paulo, além de Niterói, no estado do Rio de Janeiro, destacam-se dentre os cinco maiores valores para o IDIM. Por outro lado, as cidades de Bodó e Santa Cruz de Salinas, em Minas Gerais, o município de Meridiano, em São Paulo, e Nova América, em Goiás, destacam-se com os valores mais baixos para o indicador. O porte dos municípios com maior indicador levanta a hipótese sobre alguma correlação positiva entre essas variáveis. Dos municípios com maior valor, nenhum possui uma população inferior a 260 mil habitantes. Já para as cidades com as piores colocações, nenhuma possui uma população maior do que 5 mil habitantes. Essas evidências apontam para a necessidade de um exame no tocante à correlação existente entre o IDIM e o tamanho da população, a qual não se mostrou relevante pela análise de correlação simples. ${ }^{22}$

${ }^{21}$ Baseado em Soares et al. (2011), empregou-se uma média ponderada dos fatores extraídos por Componentes Principais para a construção do índice, utilizando como peso de ponderação as respectivas variâncias compartilhadas por cada fator.

22 O IDIM apresentou uma correlação de 0,1396 com o tamanho da população estimada para 2014. Foram testadas, também, as correlações do IDIM com a distância dos municípios à capital do estado, 
A Figura 1 apresenta o mapa de distribuição do IDIM, por dispersões do valor médio, para os municípios brasileiros.

A análise visual do mapa não permite conclusões a respeito dos possíveis padrões de associação da variável entre os municípios. No entanto, como ressalta Almeida (2012), é preciso fazer um estudo mais aprofundado para poder afirmar se as observações são distribuídas aleatoriamente ou se seguem um padrão espacial sistemático. Assim, com a Análise Exploratória do Dados Espaciais - AEDE - evita-se o problema do viés causado pelo "olhar humano", que sempre busca padrões e estruturas em todos os aspectos da realidade.

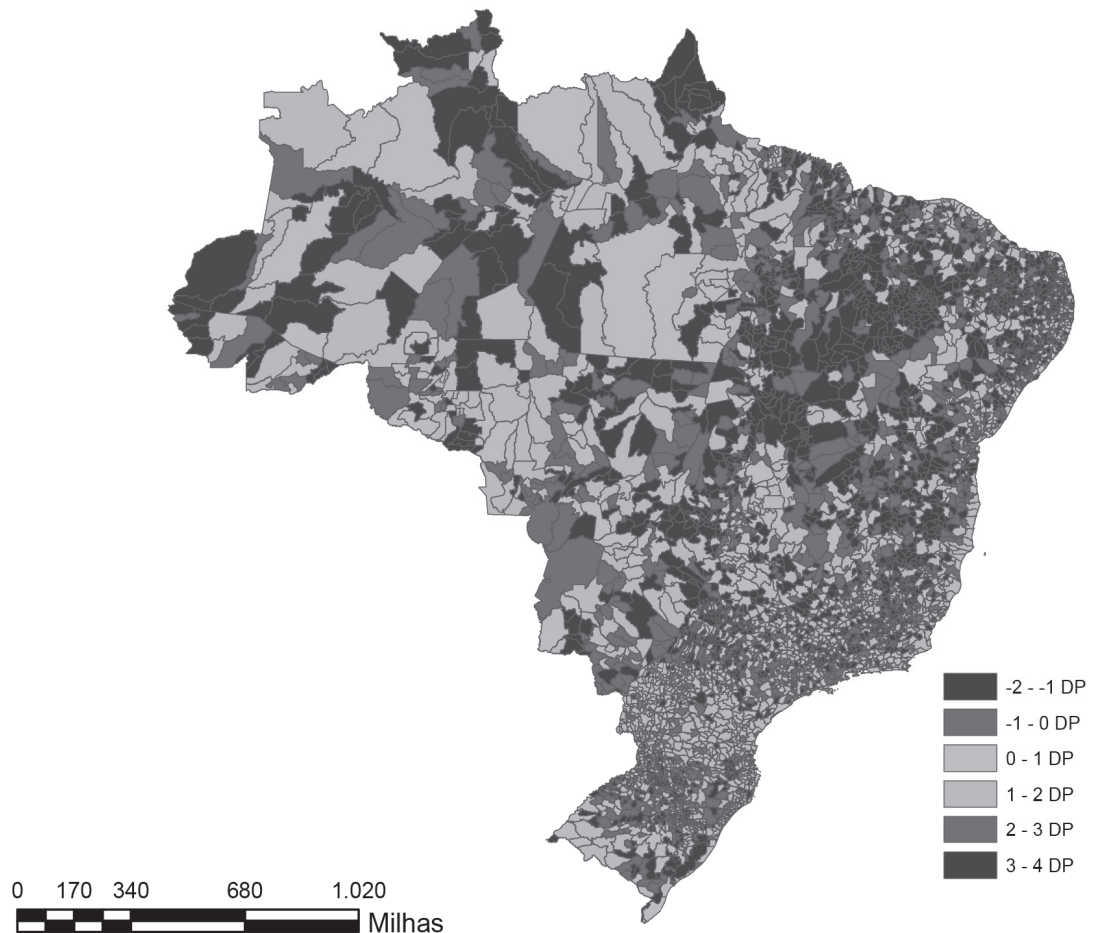

Figura 1 - Mapa da distribuição do IDIM no território nacional.

Notas: Uso do software ArcGIS 10.5. DP é o desvio-padrão e o ponto zero é a média. Fonte: Elaboração dos autores.

à capital federal e ao fato de o município ser capital (por meio de uma dummy que assume valor 1 se o município é capital). Os resultados foram, respectivamente, iguais a -0,0972, 0,0091 e 0,0785. 
O resultado para o I de Moran global, construído a partir de uma matriz de pesos espaciais do tipo Queen de primeira ordem, é igual a 0,3809, ${ }^{23}$ e este resultado é maior do que o valor esperado para o indicador $(-0,00018) .{ }^{24}$ Portanto, pode-se dizer que há uma similaridade entre o comportamento das instituições dos municípios em relação às dos vizinhos. Entretanto, uma autocorrelação positiva para o I de Moran global não garante que todos os municípios terão o mesmo comportamento (ou seja, vizinhos terão comportamentos semelhantes). Para se ter uma análise mais detalhada da distribuição espacial do IDIM, emprega-se uma medida de autocorrelação espacial local (LISA). O mapa de cluster LISA, que combina a informação do diagrama de dispersão de Moran e a do mapa de significância das medidas de associação local I, pode ser visualizado na Figura 2.

O mapa a seguir revela a existência de grupos de municípios com características semelhantes. Portanto a hipótese de homogeneidade espacial do IDIM é rejeitada. Observam-se algumas ilhas de influência do tipo Alto-Alto na região Sul, Centro Oeste e Sudeste, ou seja, municípios com elevado índice possuem vizinhos com índices também altos. Quanto às regiões Norte e Nordeste, predominam clusters do tipo Baixo-Baixo, o que indica que municípios com um valor baixo do indicador possuem vizinhos com indicadores também baixos. Vale destacar que o IDIM apresentou pontos do tipo Alto-Baixo e uma provável dinâmica de divisão "norte-sul" no território nacional.

${ }^{23}$ Valor estatisticamente significativo, com um pseudo p-valor de 0,001, obtido a partir de 999 permutações aleatórias.

${ }^{24}$ De acordo com Cliff e Ord (1981) apud Almeida (2012), o I de Moran tem um valor esperado, ou seja, aquele que seria obtido caso não houvesse padrão espacial nos dados, de -[1/(n-1)], onde n é o número de regiões. 


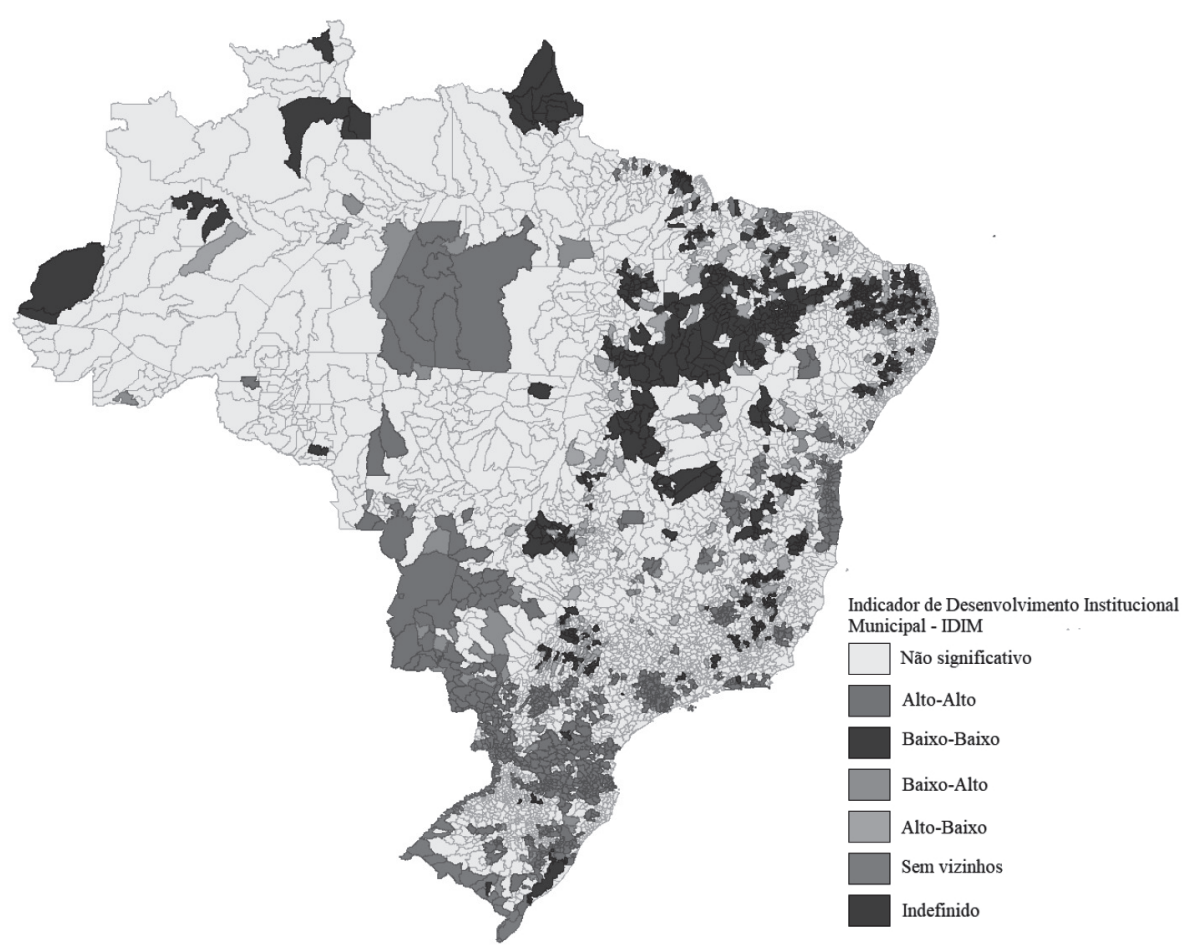

Figura 2 - Cluster LISA para o IDIM

Nota: Uso do software Geoda

Fonte: Elaboração dos autores.

As regiões sul e sudeste apresentam o maior número de municípios com clusters do tipo Alto-Alto, tendo o Sul com 220 municípios e o Sudeste com 177. Por outro lado, a região norte apresenta o menor número de municípios em clusters do tipo alto-alto. Dentre os estados do sul do país, Santa Catarina se destaca pela maior quantidade de municípios nessa categoria. Citam-se as cidades de Ituporanga, Rio do Sul, Joaçaba, Rio das Antas e Presidente Getúlio com os maiores valores para o índice institucional. Essas cidades têm em comum um Índice de Desenvolvimento Humano (IDH) alto ou muito alto, de acordo com o Programa das Nações Unidas para o Desenvolvimento (PNUD), em 2010. Ademais, todos os municípios realizam consórcio público nas áreas de educação, de assistência e desenvolvimento, de cultura, de meio-ambiente, de desenvolvimento urbano e de saneamento básico. 
Com relação ao cluster do tipo Baixo-Baixo, tem-se uma maior representatividade na região nordeste, com 433 municípios. O estado do Piauí lidera com o maior número de municípios com clusters desse tipo. Destacam-se, com os cinco piores indicadores IDIM do estado, as cidades de Landri Sales, Agricolândia, São João do Arraial, Sebastião Leal e São João da Canabrava. Estas cidades têm, em comum, valores de IDH médio ou baixo e populações menores do que 7.500 habitantes, de acordo com o Instituto Brasileiro de Geografia e Estatística (IBGE), em 2010.

No que concerne ao cluster Alto-Baixo, novamente a região nordeste lidera o ranking da categoria, com 66 municípios, de um total de 114 cidades. O estado do Maranhão apresenta o maior número de cidades com o IDIM alto, circundadas por cidades com o indicador baixo, comparativamente aos demais estados da região. As cidades Barra do Corda, Bacabal, Imperatriz, Codó e Santa Inês se destacam com os cinco melhores indicadores dentre as cidades do estado, para a categoria Alto-Baixo. Além de apresentarem populações maiores do que 80 mil habitantes, estes municípios fazem, em sua maioria, contingência com cidades com populações e PIB per capita baixos. Isto remete à lógica de cidades pólos, as quais influenciam (e são influenciadas) pelas dinâmicas socioeconômicas da vizinhança.

Após a construção e análise do IDIM, parte-se para o modelo empírico que capta o efeito deste indicador sobre o desempenho econômico dos municípios brasileiros.

\subsection{Impacto do indicador na economia dos municípios}

Diante da detecção da autocorrelação espacial, reforça-se a importância da utilização de controles espaciais. Além disso, deve-se controlar a causalidade reversa que pode existir entre indicador institucional e o crescimento econômico. Engerman e Sokoloff (2002), Acemoglu et al. (2005), Naritomi (2007) e Pereira et al. (2011) consideram os determinantes geográficos e históricos como elementos de controle da endogeneidade institucional. Baseado em Menezes-Filho et al. (2006), que demonstraram que os aspectos geográficos se sobressaem aos históricos como variáveis de controle, consideram-se as variáveis latitude, precipitação média anual e temperatura média anual como controles da endogeneidade. 
A Tabela 6 apresenta os resultados da regressão do IDIM em primeiro estágio (8). No que se refere à latitude dos municípios, os resultados corroboram aos achados de Leivas et al. (2015), demonstrando que, para o Brasil, as cidades mais próximas à linha do Equador apresentam arranjos institucionais piores. No que se refere à temperatura média e média de chuvas, os resultados encontrados são análogos aos de Pereira et al. (2011), além da própria latitude. Isso demonstra que municípios mais quentes apresentam instituições piores e aqueles que possuem um nível maior de chuvas, instituições melhores. Todos esses resultados são estatisticamente significativos a $5 \%$.

A partir da regressão de primeiro estágio, obtém-se o valor predito para o IDIM, corrigida a endogeneidade. Com isso, realiza-se a regressão, por Mínimos Quadrados Ordinários (MQO), do nível de renda dos municípios em função dos seus aspectos institucionais, como apresentado na Tabela 7.

O diagnóstico dos resíduos do modelo estimado por MQO demonstra a necessidade de especificação da forma econométrica espacial para o modelo que tem o PIB per capita como variável dependente. Isso pode ser constatado por meio do I de Moran, que apresentou um valor positivo e com pseudo-significância estatística elevada, indicando, assim, a existência de autocorrelação espacial. Ademais, os resultados dos testes de KoenketBasset e Jarque-Bera indicam que o termo de erro é, respectivamente, heterocedástico e não apresenta distribuição normal. Assim sendo, a estimação do Spatial Durbin Model (SDM) deve ser feita por meio do método de mínimos quadrados em dois estágios (MQ2E), com termos de erro robustos, como apresentado na Tabela 8.

Tabela 6 - Estimação do IDIM em primeiro estágio

\begin{tabular}{lcc}
\hline Variáveis & Coeficientes & P-valor \\
\hline Constante & 0,0772 & 0,07 \\
Despesa de capital per capita (linearizada) & $-0,0137$ & 0,00 \\
Número de escolas com complexidade média (linearizada) & 0,0569 & 0,00 \\
Latitude & $-0,0069$ & 0,00 \\
Precipitação pluviométrica média anual & 0,0004 & 0,00 \\
Temperatura média anual & $-0,0034$ & 0,01 \\
Borda ${ }^{1}$ & 0,3891 & 0,00 \\
\hline
\end{tabular}

${ }^{1}$ Variável dummy que assume valor 1 se o município faz contiguidade com fronteiras litorâneas ou com outros países. É usada como controle para o efeito de beirada (Almeida 2012).

Nota: Erros padrão robustos.

Fonte: Elaboração própria dos autores. 
Tabela 7 - Estimação do PIB per capita (linearizado) por MQO

\begin{tabular}{lcc}
\hline Variáveis & Coeficientes & P-valor \\
Constante & 7,7797 & 0,06 \\
IDIM predito em primeiro estágio & 6,0758 & 0,00 \\
Despesa de capital per capita (linearizada) & 0,2084 & 0,00 \\
Número de escolas com complexidade média (linearizada) & $-0,2600$ & 0,00 \\
Borda & $-1,1586$ & 0,00 \\
\hline Diagnóstico & & \\
Koenker-Basset & 0,00 & 0,00 \\
Jarque-Bera & 1897,00 & 0,00 \\
I de Moran' & 0,42 & 0,00 \\
\hline
\end{tabular}

${ }^{1}$ A pseudosignificância empírica foi baseada em 999 permutações aleatórias.

Fonte: Elaboração própria dos autores.

Tabela 8 - Estimação do SDM por MQ2E

\begin{tabular}{lcc}
\hline Variáveis & Coeficientes & P-valor \\
Constante & 7,2096 & 0,00 \\
IDIM estimado em primeiro estágio & 7,6012 & 0,00 \\
Despesa de capital per capita (linearizada) & 0,2094 & 0,00 \\
Número de escolas com complexidade média (linearizada) & $-0,3317$ & 0,00 \\
Borda & $-0,1526$ & 0,00 \\
\hline PIB per capita (linearizado) defasado espacialmente & 0,0395 & 0,04 \\
IDIM estimado defasado espacialmente & $-2,1093$ & 0,02 \\
Despesa de capital per capita (linearizada) defasada espacialmente & 0,0632 & 0,23 \\
Número de escolas com complexidade média (linearizada) defasada espacialmente & 0,0710 & 0,25 \\
\hline
\end{tabular}

Fonte: Elaboração própria dos autores.

Os resultados demonstram que o PIB per capita dos municípios vizinhos afeta positivamente o desempenho do município, o que pode estar refletindo os transbordamentos e oportunidades econômicas que podem ocorrer em aglomerados de cidades mais próximas. Para se fazer inferências de modelos com dependência espacial deve-se levar em conta os transbordamentos, que são captados pelos efeitos diretos e indiretos. Os efeitos diretos médios apresentam o impacto marginal que uma determinada variável explicativa na região i tem sobre a variável explicada da mesma região, já 
os efeitos indiretos médios captam o impacto que a média de uma variável explicativa $\mathrm{x}$ em todas as $\mathrm{n}$ regiões vizinhas à região analisada, $\mathrm{i}$, têm sobre a sua variável dependente. Por último, o efeito marginal total compreende a soma dos efeitos direto e indireto, representando o impacto médio do regressor sobre o regressando, considerados os efeitos do espraiamento (Almeida 2012). Sendo assim, a Tabela 9 apresenta os efeitos diretos, indiretos e total.

Tabela 9 - Impactos médios sobre o PIB per capita (linearizado) dos municípios

\begin{tabular}{lcc}
\hline & $\mathrm{d} / \mathrm{dy}$ & P-valor \\
\hline Direto & & \\
IDIM estimado em primeiro estágio & 7,587 & 0,00 \\
Despesa de capital per capita (linearizada) & 0,201 & 0,00 \\
Número de escolas com complexidade média (linearizada) & $-0,331$ & 0,00 \\
Borda & $-0,153$ & 0,00 \\
\hline Indireto & & \\
IDIM estimado em primeiro estágio & $-1,856$ & 0,03 \\
Despesa de capital per capita (linearizada) & 0,073 & 0,00 \\
Número de escolas com complexidade média (linearizada) & 0,059 & 0,24 \\
Borda & 0,006 & 0,28 \\
\hline Total & & \\
IDIM estimado em primeiro estágio & 6,179 & 0,00 \\
Despesa de capital per capita (linearizada) & 0,217 & 0,00 \\
Número de escolas com complexidade média (linearizada) & $-0,309$ & 0,00 \\
Borda & $-0,332$ & 0,00 \\
\hline
\end{tabular}

Fonte: Elaboração própria dos autores.

O resultado do efeito direto (e o efeito total, que considera além do impacto direto os espraiamentos) para o IDIM aponta que as instituições apresentam uma relação causal positiva e altamente significativa na determinação do PIB per capita municipal. Este resultado vai ao encontro da teoria institucional que defende que instituições importam à medida que criam mecanismos de promoção e manutenção do desenvolvimento. Mais do que isso, o sinal positivo do parâmetro indica que o Estado, por meio de suas instituições formais, pode ser capaz de influenciar positivamente o PIB per capita dos municípios. Assim, sugere-se que as disparidades econômicas observadas entre os municípios brasileiros também têm uma 
explicação nas diferenças dos seus respectivos arranjos institucionais, cabendo aos gestores de políticas públicas uma avaliação das possibilidades de melhoria desses arranjos para que o desenvolvimento socioeconômico seja fomentado.

No tocante à proxy para capital físico, obtém-se um valor positivo e significativo para o parâmetro, corroborando com a teoria que aponta que o capital físico é relevante para a determinação do PIB per capita de forma direta. A proxy para capital humano, por sua vez, apresenta uma relação direta negativa e estatisticamente significativa com o nível de renda dos municípios. De acordo com Figueirêdo (2011), a análise do capital humano como determinante do desempenho econômico encontra resultados muitos distintos na literatura empírica. Isso pode ser decorrência da dificuldade de obtenção de uma proxy que capte de forma eficaz a capacitação técnica e intelectual da região analisada.

No tocante aos impactos indiretos, percebe-se que o arcabouço institucional das cidades vizinhas afeta negativamente o desenvolvimento do município, ou seja, quanto melhor a qualidade institucional dos vizinhos, menor é o desempenho econômico médio dos municípios, com um nível de significância estatística de $5 \%$. Tal resultado é parecido com o encontrado por Leivas et al. (2015). Isso pode estar refletindo, para uma análise estática, que no curto prazo esteja ocorrendo uma maior captação de investimentos para determinados municípios com um arcabouço institucional mais acurado, podendo afetar negativamente os vizinhos. No que se refere à despesa de capital das cidades vizinhas, percebe-se um impacto positivo e estatisticamente significativo sobre o município.

\section{Considerações finais}

O presente estudo buscou mensurar um indicador institucional multidimensional municipal que fosse capaz de captar as diferenças institucionais, baseadas na ação do Estado, além de inserir essa medida como variável explicativa da dinâmica econômica dos municípios (expressa pelo valor do PIB per capita). 
O Indicador de Desenvolvimento Institucional Municipal (IDIM) contempla múltiplas áreas interligadas à discussão institucional sob a ótica do Estado, como, por exemplo, a realização de consórcios públicos, que está diretamente relacionada à ideia de incentivo à cooperação. Ademais, o indicador contempla aspectos sobre direitos humanos e outros relacionados à própria organização territorial.

A partir da construção do IDIM, torna-se possível avaliar quais municípios são institucionalmente "mais fracos" do que outros, sob o prisma da organização institucional da gestão pública municipal. Além disso, o indicativo de que municípios com um valor alto para o indicador estão rodeados por municípios com um índice também alto pode estar representando as sinergias institucionais positivas que são criadas quando os municípios de uma determinada microrregião formam uma rede de cooperação por meio dos consórcios públicos, por exemplo. Entretanto, a inclusão do indicador institucional defasado espacialmente sugere que os aspectos institucionais dos municípios vizinhos se associam negativamente ao PIB per capita municipal, ao menos no curto prazo.

A proposta do indicador institucional para municípios e a análise da sua relação com o desempenho socioeconômico alimenta o debate acerca do papel institucional do Estado como agente capaz de reduzir conflitos, ampliar oportunidades de cooperação e de organização territorial. Para os próximos trabalhos fica o esforço da avaliação temporal desse tipo de indicador institucional multidimensional, com intuito de captar a evolução desse instrumento e seu impacto ao longo do tempo sobre a dinâmica econômico das regiões brasileiras.

\section{Referências}

Abrucio, F. L., e P. Laczyzsnki. 2013. "Desigualdade e Cooperação Federativa: um novo olhar para a discussão dos consórcios." Consórcios públicos e as agendas do Estado brasileiro. São Paulo: Fundação Perseu Abramo.

Acemoglu, Daron, Simon Johnson, e James A. Robinson. 2002. "Reversal of fortune: Geography and institutions in the making of the modern world income distribution." The Quarterly journal of economics 117, no.4: 1231-1294. Acemoglu, Daron, Simon Johnson, e James A. Robinson. 2005.'Institutions as a fundamental cause of long-run growth." Handbook of economic growth 1: 385-472.

Acemoglu, Daron, e James A. Robinson. 2008. "Persistence of power, elites, and institutions." American Economic Review 98, no.1: 267-93. 
Alcalá, Francisco, e Antonio Ciccone. 2004. "Trade and productivity." The Quarterly journal of economics 119, no.2: 613-646.

Almeida, Eduardo. 2012. Econometria espacial. Campinas-SP: Alínea.

Alves, Vladimir. 2006. Comentários à lei dos consórcios públicos. Leud.

Alves, Maria Teresa Gonzaga, e José Francisco Soares. 2013. "Contexto escolar e indicadores educacionais: condições desiguais para a efetivação de uma política de avaliação educacional.” Educação e pesquisa 39, no.1: 177-194.

Anderson, George. 2009. Federalismo: uma introdução. São Paulo: Editora FGV.

Anselin, Luc. 1995. "Local indicators of spatial association—LISA." Geographical analysis 27, no.2: 93-115.

Anselin, Luc. 2013. Spatial econometrics: methods and models. Vol. 4. Springer Science \& Business Media.

Baldissera, Darlan Sampietro. 2015. “Consórcios públicos intermunicipais no Brasil: panorama após os 10 anos da Lei 11.107/2005”. Tese de doutorado, FGV.

Barreto, Ricardo Candéa Sá, Eduardo Simões Almeida, e João Eustaquio de Lima. 2010. "Convergência espacial do PIB per capita no estado do Ceará." Revista de Economia 36, no.3.

Barro, Robert J., e Xavier Sala-i-Martin. 1995. Technological Diffusion, Convergent, and Growth. National Bureau of Emnomic Research. No. 5151. Working paper.

Bartlett, Maurice S. 1954. "A note on the multiplying factors for various $\chi 2$ approximations." Journal of the Royal Statistical Society. Series B (Methodological): 296-298.

Baumont, Catherine. 2004. "Spatial effects in housing price models: do housing prices capitalize urban development policies in the agglomeration of Dijon (1999)?".

Benesty, Jacob, et al. 2009. "Pearson correlation coefficient." Noise reduction in speech processing. Springer, Berlin, Heidelberg. 1-4.

Bosker, Maarten, e Harry Garretsen. 2009. "Economic development and the geography of institutions." Journal of Economic Geography 9, no.3: 295-328.

Brasil. Ministério da Educação. Disponível em: <https://www.mec.gov.br/>. Atualização 2013. Acesso em maio de 2019.

Brasil. Ministério do Planejamento, Orçamento e Gestão. Disponível em: < http://www.planejamento.gov.br/>. Atualização 2015. Acesso outubro de 2019.

Censo, IBGE. Disponível em:< http://www. censo2010. ibge. gov. br/>. Acesso em julho de 2018, v. 23, 2010.

Chang, Ha-Joon. 2003. Globalization, economic development and the role of the state. Zed Books.

Consórcios Públicos Intermunicipais: Uma Alternativa à Gestão Pública - Brasília: CNM, 2016. Disponível em: $<$ http://www. cnm.org.br/>. Acesso em novembro de 2019.

Conceição, Octávio Augusto Camargo. 2002. "A relação entre processo de crescimento econômico, mudança e instituições na abordagem institucionalista." Ensaios FEE 23: 603-620.

Cronbach, Lee J. 1951. "Coefficient alpha e the internal structure of tests." psychometrika 16, no.3: 297-334

Cunha, Rosani Evangelista da. 2004. "Federalismo e relações intergovernamentais: os consórcios públicos como instrumento de cooperação federativa".

Da Hora, Henrique Rego Monteiro, Gina Torres Rego Monteiro, e José Arica. 2010. “Confiabilidade em questionários para qualidade: um estudo com o Coeficiente Alfa de Cronbach.” Produto \& Produção 11, no.2.

De Melo, Carmem Ozana, e José Luiz Parré. 2006. "Determinantes do desenvolvimento rural dos municípios da região sudoeste paranaense." Revista Faz Ciência 8, no.1: 11.

Easterly, William, e Ross Levine. 2002. "Tropics, germs, and crops: how endowments influence economic development." Journal of monetary economics 50, no.1: 3-39.

Engerman, Stanley L., e Kenneth L. Sokoloff. 2002. Factor endowments, inequality, and paths of development among new world economics. No. w9259. National Bureau of Economic Research. 
Fávero, Luiz, e Patrícia Belfiore. 2015. Análise de dados: técnicas multivariadas exploratórias com SPSS e STATA. Elsevier Brasil.

Fiani, Ronaldo. 2002. "Crescimento econômico e liberdades: a economia política de Douglass North.” Economia e sociedade 11, no.1: 45-62.

Figueirêdo, Lízia. 2011. “Incerteza sobre o impacto do capital humano na desigualdade de renda no Brasil.” Revista Economia \& Tecnologia 7, no.1.

Firme, Vinícius de Azevedo Couto, and José Simão Filho. 2014. "Análise do crescimento econômico dos municípios de minas gerais via modelo MRW (1992) com capital humano, condições de saúde e fatores espaciais, 1991-2000." Economia Aplicada 18, no.4: 679-716.

Ferreira, Aurélio Buarque de Holanda. 2004. "Novo dicionário Aurélio da língua portuguesa." Novo dicionário Aurélio da lingua portuguesa.

Freitas, A. L. P., e S. G. Rodrigues. 2005. “A avaliaçao da confiabilidade de questionário: uma análise utilizando o coeficiente alfa de Cronbach. In: Simpósio de Engenharia de Produção.” Anais... Bauru-SP: UNESP.

Guilford, Joy Paul. 1950. "Fundamental statistics in psychology and education".

Hall, Robert E., and Charles I. Jones. 1999. "Why do some countries produce so much more output per worker than others?" The quarterly journal of economics 114, no.1: 83-116.

Kaiser, Henry F. 1958. "The varimax criterion for analytic rotation in factor analysis." Psychometrika 23, no.3: 187-200.

Kaiser, Henry F. 1970. "A second generation little jiffy".

Keinert, Tania Margarete Mezzomo, Tereza Etsuko da Costa Rosa, e Marco Meneguzzo. 2006. Inovação e cooperação intergovernamental: microrregionalização, consórcios, parcerias e terceirização no setor saúde. Annablume.

Kroth, Darlan Christiano, e Joilson Dias. 2012. "Os efeitos dos investimentos público e privado em capitais físico e humano sobre o produto per capita dos municípios da região Sul: uma análise em painéis de dados dinâmicos.” Nova Economia 22, no.3: 621-649.

Leivas, Pedro Henrique Soares, et al. 2015. "A geografia das instituições: uma abordagem espacial para os municípios brasileiros." Revista Brasileira de Estudos Regionais e Urbanos 9, no.2: 169-185.

LeSage, James P., e Manfred M. Fischer. 2008. "Spatial growth regressions: model specification, estimation and interpretation." Spatial Economic Analysis 3, no.3: 275-304.

LeSage, James, e Robert Kelley Pace. 2009. Introduction to spatial econometrics. Chapman and Hall/CRC.

LeSage, James P., e R. Kelley Pace. 2014. "The biggest myth in spatial econometrics." Econometrics 2, no.4: 217-249.

Linhares, Paulo de Tarso Frazão, Constantino Cronemberger Mendes, e Antonio Lassance. 2012. "Federalismo à brasileira: questões para discussão".

Lira, Sachiko Araki, e Anselmo Chaves Neto. 2004. "Pontos de dicotomização para a obtenção do coeficiente de correlação tetracórico." RECEN-Revista Ciências Exatas e Naturais 7, no.2: 195-208.

Lucas, Robert. 1988. "On the mechanics of economic development." Journal of monetary economics.

Mankiw, N. Gregory, David Romer, e David N. Weil. 1992. "A contribution to the empirics of economic growth." The quarterly journal of economics 107, no.2: 407-437.

Marshall, Alfred. 1890. Some aspects of competition. Harrison and Sons.

Matos, Celso Augusto, e Ricardo Teixeira Veiga. 2000. “Avaliação da qualidade percebida de serviços: um estudo em uma organização não-governamental." Caderno de Pesquisas em Administração 7, no.3: 27-42.

Menezes-Filho, Naércio, et al. 2006. "Instituições e diferenças de renda entre os estados brasileiros: uma análise histórica." XXXIV Encontro Nacional de Economia 1.

Milan, Gabriel Sperandio, e Guilherme Trez. 2005. "Pesquisa de satisfação: um modelo para planos de saúde." RAE eletrônica 4, no.2: 0-0. 
Mingoti, Sueli Aparecida, et al. 2007. "Análise de dados através de métodos de estatística multivariada: uma abordagem aplicada".

Naritomi, Joana. 2007. "Herança colonial, instituições e desenvolvimento." Um estudo sobre a desigualdade entre os municípios Brasileiros.

Neto, Gilberto da Silva Barros, e Luciano Nakabashi. 2011. "Relações entre instituições, capital humano e acumulação de capital físico nos municípios brasileiros." Revista Economia \& Tecnologia 7.2.

Neto, Gilberto Da Silveira Barros, Luciano Nakabashi, e Armando Vaz Sampaio. 2014. "Determinantes do capital físico: o papel do capital humano e da qualidade institucional." Anais do XLI Encontro Nacional de Economia. No. 099. ANPEC-Associação Nacional dos Centros de Pós-Graduação em Economia.

North, Douglass C. 1990. Institutions, institutional change and economic performance. Cambridge university press.

North, Douglass C., e Robert Paul Thomas. 1973. The rise of the western world: A new economic history. Cambridge University Press.

Pagan, Acácio Alexandre, EL-HANI Charbel, e Nélio Bizzo. 2012. “A identidade humana e o alter vivo: concepções de alguns alunos de Ciências Biológicas." Revista de Educação Pública 20, no.44: 445-461.

Pande, Rohini, e Christopher Udry. 2005. "Institutions and development: A view from below." Yale University Economic Growth Center Discussion Paper 928.

Pereira, Ana Elisa Gonçalves, Luciano Nakabashi, e Adolfo Sachsida. 2011. Qualidade das Instituições e PIB per capita nos Municípios Brasileiros. No. 1623. Texto para Discussão.

Pereira, Ana Elisa Gonçalves, Luciano Nakabashi, e Márcio A. Salvato. 2012. "Instituições e nível de renda: uma abordagem empírica para os municípios paranaenses.” Nova Economia 22, no.3: 597-620.

Pereira, Greisson Almeida, e Tito Belchior da Silva Moreira. 2016. "Consórcio Público Intermunicipal: características dos municípios participantes.” Revista de Políticas Públicas 20, no.1: 307-325.

Rodrik, Dani, Arvind Subramanian, e Francesco Trebbi. 2004. "Institutions rule: the primacy of institutions over geography and integration in economic development." Journal of economic growth 9, no.2: 131-165.

Sachs, Jeffrey. "Notes on a new sociology of economic development. 2000. "Culture matters: How values shape human progress, ed: $29-43$.

Santana, Adrielli Santos, e Ricardo Candéa Sá Barreto. 2016. "Qualidade institucional e desempenho econômico: análise empírica dos municípios brasileiros, 2010." Revista Brasileira de Estudos Regionais e Urbanos 10, no.2: $253-271$.

Senem, Arno, e Marlon Jorge Teza. 2015. "Análise da ação preventiva da polícia militar no município: o poder de polícia do município e implicações na ordem pública." Revista Ordem Pública 8, no.1: 239-260.

Silva, Fernando. 2006. Desafios do federalismo fiscal. Editora FGV.

Silva, Alexandre Manoel, e Guilherme Mendes Resende. 2009. "Crescimento econômico comparado dos municípios alagoanos e mineiros: uma análise espacial.” Revista Economia Política do Desenvolvimento 1, no.6: 135.

Silva, Jonathas de Melo Cristovão, Monica Yukie Kuwahara, e Vladimir Fernandes Maciel. 2012. "A eficiência dos gastos municipais na geração de bem-estar na região metropolitana de São Paulo." RDE-Revista de Desenvolvimento Econômico 14, no.26.

Soares, Ana Cristina Lima Gouveia et al. 2011. "Índice de desenvolvimento municipal: hierarquização dos municípios do Ceará no ano de 1997”. Revista Paranaense de Desenvolvimento-RPD 97: 71-89.

Stakhovych, Stanislav, e Tammo HA Bijmolt. 2009. "Specification of spatial models: A simulation study on weights matrices." Papers in Regional Science 88, no.2: 389-408.

Tobler, Waldo R. 1970. “A computer movie simulating urban growth in the Detroit region.” Economic geography 46.sup1: 234-240.

Urdan, André Torres. 2001. “A qualidade de serviços médicos na perspectiva do cliente." Revista de Administração de Empresas 41, no.4: 44-55. 